\title{
Short Communication Insulin-like growth factors and liver cancer risk in male smokers
}

\author{
JM Major ${ }^{*, 1}$, RZ Stolzenberg-Solomon', MN Pollak ${ }^{2}, K_{\text {Snyder }}{ }^{3}, J$ Virtamo $^{4}$ and D Albanes' \\ 'Division of Cancer Epidemiology and Genetics, National Cancer Institute, NIH, Bethesda, MD 20852, USA; 'Department of Oncology, Jewish General \\ Hospital and McGill University, Montreal, Quebec, Canada H3T IE2; ${ }^{3}$ Information Management Services Inc., Silver Spring, MD 20904, USA; \\ ${ }^{4}$ Department of Chronic Disease Prevention, National Institute for Health and Welfare, Helsinki 00300, Finland
}

\begin{abstract}
BACKGROUND: The liver is the primary source of circulating insulin-like growth factor (IGF)-I, yet the relation between IGFs and liver cancer is uncertain.

METHODS: In a case-cohort study within a cohort of 29 I 33 male smokers we examined associations of serum IGF-I and IGF binding protein (IGFBP)-3 with liver cancer (50 cases).

RESULTS: Nonlinear associations between liver cancer and IGF-I and IGFBP-3 were observed $(P=0.04$ and $P<0.0$ I, respectively),

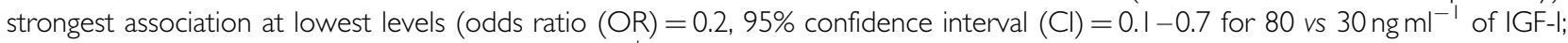
$\mathrm{OR}=0.2,95 \% \mathrm{Cl}=0.1-0.6$ for 1400 vs $700 \mathrm{ng} \mathrm{ml} \mathrm{I}^{-1}$ of IGFBP-3).

CONCLUSIONS: LOW IGF-I and IGFBP-3 levels in male smokers are associated with increased risk of liver cancer.

British Journal of Cancer (2010) 103, 1089-1092. doi:I0.1038/sj.bjc.6605842 www.bjcancer.com

Published online 17 August 2010

(c) 2010 Cancer Research UK
\end{abstract}

Keywords: insulin-like growth factor; IGF-l; incidence; men

Liver cancer is the fifth most common cancer worldwide (Bosch et al, 2004), occurs more commonly in men, and has a high fatality among affected patients. Although populations of developing countries have the highest risk with the primary cause being hepatitis B virus (HBV) infection, a trend of increasing incidence has been observed in developed countries (McGlynn et al, 2001). Hepatocellular carcinoma (HCC) accounts for over $85 \%$ of cases, but underlying mechanisms of hepatocarcinogenesis are not completely understood and may vary across risk factors (Scharf and Braulke, 2003).

The liver is the primary source of circulating insulin-like growth factor(IGF)-I, a peptide hormone of which levels peak at puberty and decrease thereafter (Juul, 2003; Pavelic et al, 2007). IGF-I has been implicated in the regulation of cancer cells through effects on proliferation, differentiation, and apoptosis (Dunn et al, 1997; Pollak, 2000; Moschos and Mantzoros, 2002; Sachdev and Yee, 2007). Pituitary secretion of growth hormone stimulates hepatic IGF-I production, and more than $75 \%$ of circulating IGF-I is bound and regulated by IGF binding protein (IGFBP)-3 (Ferry et al, 1999). Although previous studies showed an association between high serum concentrations of IGF-I and risk of prostate, colorectal, and breast cancers (Rowlands et al, 2009; Chan et al, 1998, 2002; Ma et al, 1999; Yu et al, 2002; Renehan et al, 2004), subsequent studies have found low IGF-I levels to be associated with an increased risk for brain and kidney cancer (Lonn et al, 2007; Major et al, 2010). Clinical studies suggest a possible inverse IGF-liver function association, although reverse causality, with low IGF-I levels being a consequence of liver damage, remains a possibility (Wu et al, 1988; Buzzelli et al, 1993). Several studies reported the reduced IGF levels to be independent of liver function and

*Correspondence: Dr JM Major; E-mail: Jacqueline.major@nih.gov Received 7 June 2010; revised 25 June 2010; accepted 15 July 2010; published online 17 August 2010 progression of disease, providing support for a potential causal connection (Stuver et al, 2000; Mazziotti et al, 2002; Mattera et al, 2003; Elsammak et al, 2006). However, these studies involved patients who already had cirrhosis or hepatitis C virus (HCV)related liver disease.

Unlike above investigations, the $\alpha$-Tocopherol, $\beta$-Carotene Cancer Prevention (ATBC) Study has a prospective design and involved a large population of men who, although being smokers, did not have liver cirrhosis, chronic alcohol abuse, or cancer at enrolment. In addition, the ATBC Study was conducted in Finland, a developed country with an extremely low prevalence of viral infections of the liver (e.g., HBV, HCV). We conducted a case-cohort study to assess the independent roles of IGF-I and IGFBP-3 in liver cancer aetiology in a population without preexisting diseases that are known risk factors.

\section{MATERIALS AND METHODS}

The ATBC Study was a randomised, placebo-controlled trial that evaluated the effect of supplementation with $\alpha$-tocopherol, $\beta$-carotene or both on the incidence of cancer (The ATBC Cancer Prevention Study Group, 1994). In 1985-88, 29133 eligible men in southwestern Finland, aged 50-69 years, who smoked at least five cigarettes daily, were randomised to an intervention group. Exclusion criteria included previous diagnosis of cancer (excluding non-melanoma skin cancer), liver cirrhosis, chronic alcoholism, or other medical conditions that might limit long-term participation. All study participants gave written informed consent before participation; the study was approved by the Institutional Review Boards of the National Public Health Institute in Finland and the US National Cancer Institute.

At study entry, participants completed an investigator-administered baseline questionnaire that included data on demographics, smoking habits, and medical history. Trained study staff measured 
height and weight at baseline using standard methods. Diet, including alcohol intake, was assessed with a validated selfadministered food frequency questionnaire. Fasting serum samples were collected from participants at their baseline visit and stored at $-70^{\circ} \mathrm{C}$ until analyzed. IGF assays were performed in the laboratory of Dr Pollak (McGill University, Montreal, QC, Canada). Total serum IGF-I and IGFBP-3 were measured by enzyme-linked immunosorbent assays after separation of IGFs from IGFBPs by acid-ethanol extraction (Diagnostic Systems Laboratory, Inc., Houston, TX, USA). The inter-batch assay coefficient of variation (CV) was 4.6 and $6.2 \%$ for IGF-I and IGFBP-3, respectively; the intra-batch assay CV was 5.2 and $4.2 \%$, respectively.

All participants in the current study were alive and without evidence of cancer during the first 5 years of follow-up. Incident cases of liver cancer were defined based on the International Classification of Diseases 9; codes 155.0, 155.1, and 155.2. Cases were identified through the Finnish Cancer Registry, which provides almost $100 \%$ case ascertainment (Korhonen et al, 2002). Medical records for cases with a major cancer site were reviewed centrally by two study physicians to confirm diagnoses (The ATBC Cancer Prevention Study Group, 1994). Cancers metastasised from other organ sites are not included in our complement of cases. A subcohort group of 400 men was randomly selected from the full ATBC Study population, representing the comparison group. Follow-up for the current study included time from randomisation through 31 December 1997, date of diagnosis, or date of death (whichever occurred first).

\section{Statistical analysis}

Exposures of interest included baseline serum IGF-I, IGFBP-3, and the IGF-I/IGFBP-3 molar ratio. Potential confounders included age, anthropometric measures, lifestyle factors, and medical history. IGF-I/IGFBP-3 molar ratio was calculated as a measure of bioavailability using the following conversion: $1 \mathrm{ng} \mathrm{ml}^{-1}$ IGF-I $=0.130 \mathrm{nmoll}^{-1}$ and $1 \mathrm{ng} \mathrm{ml}^{-1}$ IGFBP-3 $=0.036 \mathrm{nmoll}^{-1}$. Body mass index was calculated as weight in kilograms divided by squared height in metres $\left(\mathrm{kg} \mathrm{m}^{-2}\right)$.
General linear models adjusted for age were used to estimate least square means and standard errors to help identify potential confounders. Group comparisons for continuous variables were performed using analysis of covariance; categorical variables were compared using logistic regression. In addition, correlations between IGF-I, IGFBP-3, and covariates adjusting for age were calculated using Pearson's partial correlations in the comparison group.

Given the small number of cases $(n=50)$, IGF measures were analyzed as continuous predictors of liver cancer to maximise study power to identify associations. Logistic regression models were used to determine the appropriate functional form (e.g., linear or quadratic; Woodward, 2005). Accordingly, models for IGF-I and IGFBP-3 included a linear and a quadratic term to account for the curvilinear relation with liver cancer risk (Hosmer and Lemeshow, 2000; Jewell, 2004). IGF-I/IGFBP-3 molar ratio was modelled as a continuous linear variable. Odds ratios (ORs) and corresponding 95\% confidence intervals were estimated for age- and multivariableadjusted models. Consistent with the interpretation of a continuous variable, we report the ORs for 1-unit increments (e.g., 1-s.d.). As for nonlinear associations the estimated risks will vary across the IGF-axis, a single 'overall' OR cannot be calculated across the whole range of IGF concentrations; therefore, we report the ORs for four consecutive 1-s.d. increments.

All models included a continuous variable for age. Other variables were included in the final model if they were associated with both the exposure of interest and disease, changed the OR by at least $10 \%$, or had a $P$-value $\leqslant 0.20$ in the full model. The multivariable analyses did not include more covariates than appropriate for the given number of cases (Peduzzi et al, 1996). Possible effect modifications by body weight, cigarettes smoked, and alcohol intake were examined by evaluating interaction terms in the models; no significant interactions were observed.

\section{RESULTS}

Among the 50 incident liver cancer cases, 88\% were adenocarcinomas. Age-adjusted characteristics at baseline are shown in Table 1. On average, cases were older (mean age at

Table I Age and age-adjusted baseline characteristics of men, ATBC Study

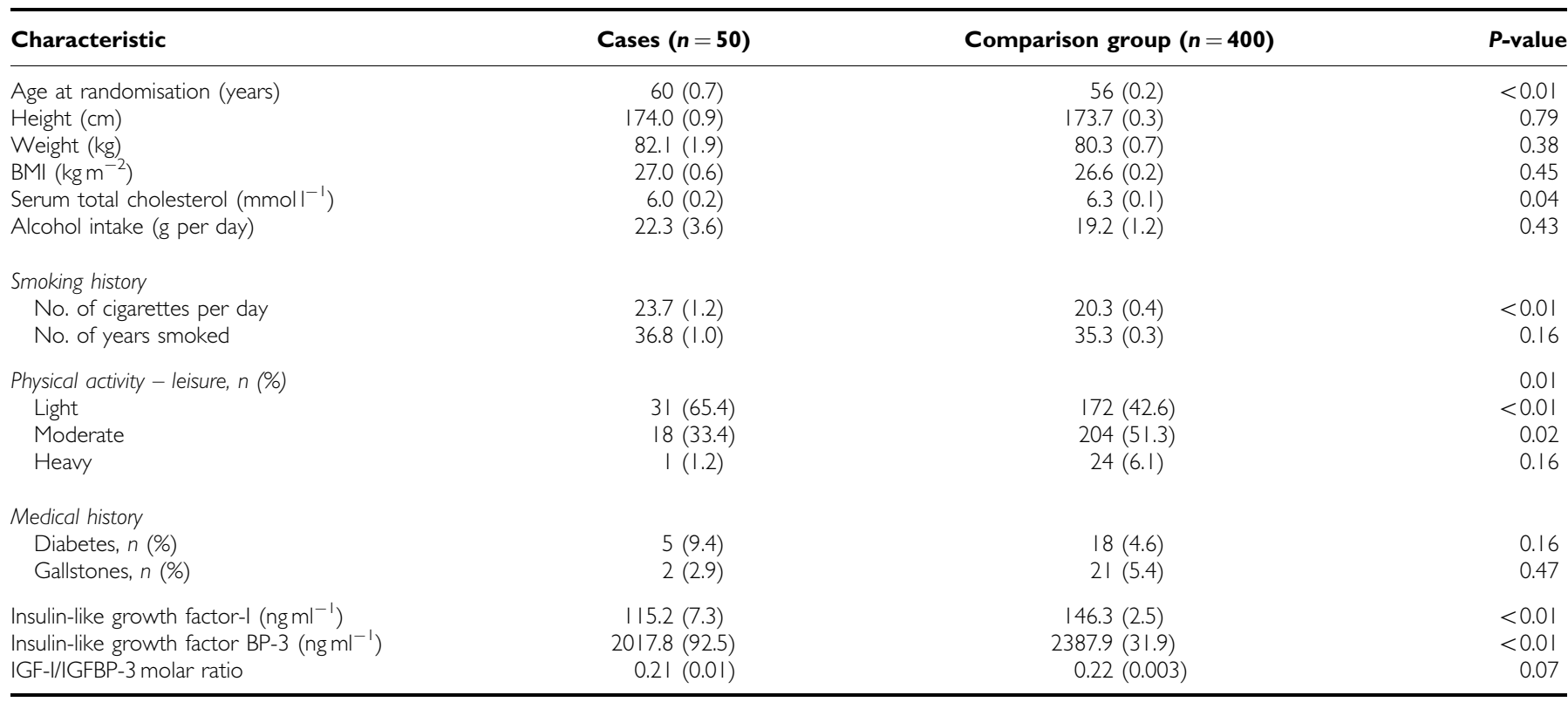

Abbreviations: ATBC $=\alpha$-Tocopherol, $\beta$-Carotene Cancer Prevention; BMI = body mass index; IGF-I = insulin-like growth factor-l; IGFBP-3 = IGF binding protein-3 Means (s.e.) are reported unless otherwise indicated. $P$-values from generalised linear models. 
Table 2 Age and age-adjusted partial correlations

\begin{tabular}{|c|c|c|c|c|}
\hline \multirow[b]{2}{*}{ Characteristic } & \multicolumn{2}{|c|}{ IGF-I } & \multicolumn{2}{|c|}{ IGFBP-3 } \\
\hline & $r$ & $P$-value & $r$ & $P$-value \\
\hline Age (years) & -0.11 & 0.03 & -0.21 & $<0.01$ \\
\hline Height $(\mathrm{cm})$ & 0.19 & $<0.01$ & 0.17 & $<0.01$ \\
\hline Weight $(\mathrm{kg})$ & 0.17 & $<0.01$ & 0.25 & $<0.01$ \\
\hline BMI $\left(\mathrm{kg} \mathrm{m}^{-2}\right)$ & 0.10 & 0.05 & 0.19 & $<0.01$ \\
\hline Serum total cholesterol $\left(\mathrm{mmol}^{-1}\right)$ & 0.07 & 0.16 & 0.21 & $<0.01$ \\
\hline Alcohol (g per day) & -0.10 & 0.04 & -0.06 & 0.22 \\
\hline No. of cigarettes per day & -0.06 & 0.22 & -0.05 & 0.32 \\
\hline No. of years smoked & -0.04 & 0.48 & -0.09 & 0.08 \\
\hline Leisure physical activity (moderate+light) & 0.09 & 0.06 & 0.12 & 0.02 \\
\hline Diabetes (yes/no) a & -0.11 & 0.03 & -0.05 & 0.36 \\
\hline History of gallstones (yes/no) & -0.01 & 0.85 & 0.07 & 0.17 \\
\hline IGFBP-3 (ng ml $\left.{ }^{-1}\right)$ & 0.69 & $<0.01$ & - & - \\
\hline
\end{tabular}

Abbreviations: $\quad \mathrm{BMI}=$ body mass index; $\mid \mathrm{GF}-\mathrm{I}=$ insulin-like growth factor-l; IGFBP-3 = IGF binding protein-3. $r$ indicates Pearson's partial correlations among noncases $(n=400)$. ${ }^{a}$ Diabetes $=$ history of diabetes and/or fasting glucose $\geqslant 126 \mathrm{mg} \mathrm{d}^{-1}$

randomisation $=60$ years), smoked more cigarettes daily, were less physically active during leisure time, and had lower serum cholesterol. Mean serum levels of IGF-I and IGFBP-3 were significantly lower in cases than in the comparison group, after adjusting for age: $115 v s 146 \mathrm{ng} \mathrm{ml}^{-1}$ and 2018 vs $2388 \mathrm{ng} \mathrm{ml}^{-1}$, respectively $(P<0.01)$. Intervention group assignment was not associated with liver cancer $(P=0.28$; data not shown).

Table 2 shows age and age-adjusted correlations of baseline participant characteristics with IGF-I and IGFBP-3. As shown, inversely correlated with serum IGF-I were age $(P=0.03)$, alcohol intake $(P=0.04)$, and having diabetes $(P=0.03)$, whereas body weight and IGFBP-3 were positively associated with IGF-I levels $(P<0.01)$, with IGFBP-3 and IGF-I having a moderately high correlation of $r=0.69$.

Age-adjusted logistic regression analyses show a significant nonlinear association between liver cancer risk and serum IGF-I and IGFBP-3 $(P<0.05$ and $P<0.01$, respectively; Table 3$)$, suggesting some curvature to the relationship between risk and IGF levels such that the ORs vary across the range of IGF values. Hence, ORs and 95\% confidence intervals (CIs) are reported for consecutive 1-s.d. intervals of $50 \mathrm{ng} \mathrm{ml}^{-1}$ for IGF-I (700 $\mathrm{ng} \mathrm{ml}^{-1}$ for IGFBP-3). In the present study, risk of liver cancer was $78 \%$ lower for men with levels of $79 \mathrm{ng} \mathrm{ml}^{-1}$ compared with $30 \mathrm{ng} \mathrm{ml}^{-1}$, $66 \%$ lower for $129 \mathrm{ng} \mathrm{ml}^{-1}$ compared with $80 \mathrm{ng} \mathrm{ml}^{-1}$, and $47 \%$ lower at $179 \mathrm{ng} \mathrm{ml}^{-1}$ compared with $130 \mathrm{ng} \mathrm{ml}^{-1}$, after adjustment for age. The ratio of cases to comparison group in the lowest range was $11: 31(35 \%)$. These results suggest that men with low levels of IGF had greater risk. Study findings were not markedly different after further adjusting for cigarettes smoked and physical activity. IGFBP-3 levels did not alter the association between serum IGF-I and risk of developing liver cancer. Similarly, risk was statistically significant for the lowest IGFBP-3 levels; IGF-I levels did not alter the risk-IGFBP-3 association (Table 3).

Although there was no evidence of a nonlinear relation $(P=0.38$ for quadratic term) between the IGF-I/IGFBP-3 molar ratio and risk, there was a suggested linear association such that for every 0.05-unit decrease in molar ratio, the odds of developing liver cancer increased by a factor of $1.35(=1.0 / 0.74)$, after adjustment for age, daily cigarettes, and physical activity $(\mathrm{OR}=0.74 ; 95 \%$ $\mathrm{CI}=0.53-1.01)$, but this was not significant $(P=0.06)$.

\section{DISCUSSION}

This is the first population-based study to prospectively examine the association of circulating IGF-I and IGFBP-3 levels with
Table 3 Associations between serum IGF measures and development of liver cancer

\begin{tabular}{|c|c|c|c|c|c|c|c|}
\hline \multirow[b]{2}{*}{ Characteristic } & \multirow[b]{2}{*}{ Cases } & \multicolumn{3}{|c|}{ Model I } & \multicolumn{3}{|c|}{ Model 2} \\
\hline & & OR & $95 \% \mathrm{Cl}$ & $P$-value & OR & $95 \% \mathrm{Cl}$ & $P$-value \\
\hline \multicolumn{2}{|c|}{$|G F-|\left(\operatorname{per} 50 n m^{-1} \mid\right)$} & & & 0.025 & & & 0.036 \\
\hline $30-79$ & | | & 0.22 & $0.10-0.48$ & & 0.24 & $0.09-0.67$ & \\
\hline $80-129$ & 24 & 0.34 & $0.21-0.54$ & & 0.38 & 0.19 & \\
\hline $130-179$ & 11 & 0.53 & $0.38-0.74$ & & 0.59 & 0.98 & \\
\hline $180+$ & 4 & 0.83 & $0.48-1.44$ & & 0.92 & $0.49-1.72$ & \\
\hline \multicolumn{2}{|c|}{ IGFBP-3 (per $700 \mathrm{ng} \mathrm{ml}^{-1}$ ) } & & & 0.002 & & & 0.004 \\
\hline $700-1399$ & 14 & 0.14 & $0.06-0.35$ & & 0.23 & $0.08-0.64$ & \\
\hline |400-2099 & 21 & 0.30 & $0.18-0.49$ & & 0.45 & $0.23-0.88$ & \\
\hline $2100-2799$ & 9 & 0.63 & $0.45-0.87$ & & 0.91 & $0.55-1.49$ & \\
\hline $2800+$ & 6 & 1.30 & $0.69-2.46$ & & 1.82 & $0.90-3.66$ & \\
\hline \multicolumn{8}{|c|}{ IGF-I/IGFBP-3 molar ratio (per 0.05 units) } \\
\hline & 50 & 0.74 & $0.54-1.01$ & 0.057 & 0.73 & $0.53-1.01$ & 0.060 \\
\hline \multicolumn{8}{|c|}{$\begin{array}{l}\text { Abbreviations: } \mathrm{Cl}=\text { confidence interval; } \mid \mathrm{GF}-\mathrm{I}=\text { insulin-like growth factor-l; } \\
\text { IGFBP-3 =IGF binding protein-3; OR =odds ratio. The association of IGF was } \\
\text { modelled as a continuous (rather than categorical) predictor of liver cancer. IGF-I and } \\
\text { IGFBP-3 were centred to prevent collinearity with the quadratic term. I-s.d. increase } \\
\text { in IGF-I =50 ng ml }{ }^{-1} \text {; I-s.d. increase in IGFBP-3=700 ng ml }{ }^{-1} \text {; P-value based on the } \\
\text { Wald test for quadratic term (IGF-I; IGFBP-3) and linear term (molar ratio). Model I: } \\
\text { age-adjusted. Model 2: adjusted for age, cigarettes per day, leisure physical activity, } \\
\text { and IGFBP-3; adjusted for age, cigarettes per day, leisure physical activity, and } \\
\text { IGF-I; adjusted for age, cigarettes per day, and leisure physical activity. }\end{array}$} \\
\hline
\end{tabular}

development of liver cancer, doing so within a cohort of older middle-aged men who, although smokers, did not have a history of alcoholism, liver cirrhosis, or previous cancer, and who resided in a country that has low prevalence of HBV and HCV infections. We observed significant nonlinear associations between IGF-I and IGFBP-3 and liver cancer risk, with the strongest association seen in the lowest IGF range. These associations were not altered markedly after adjusting for potential confounders. Interpretation of results should be made with caution, however, given the small number of cases.

Strengths of this investigation include the prospective study design of the ATBC Study, in which IGF-I and IGFBP-3 were measured from blood samples collected at the baseline visit, preceding the development of liver cancer. The possibility that IGF levels were influenced by subclinical liver cancer was minimised by selecting participants who were alive and without clinical evidence of cancer during the first 5 years of cohort follow-up. A limitation of this study was the inability to directly adjust for aflatoxin, HBV, and HCV, established risk factors for liver cancer (London and McGlynn, 2006), even though the prevalence of HBV and HCV infections in Finland is low; that is, $<0.001$ and $0.4 \%$, respectively (Iivonen et al, 2005; Shepard et al, 2005, 2006).

Our findings are consistent with those from the only other study of liver cancer and IGF-1, in which patients with HCC were found to have significantly lower IGF-I levels than age- and gendermatched controls after adjusting for prothrombin time and serum albumin levels, indicators of the degree of liver damage (Stuver et al, 2000). Given the complexity of the IGF system and the paucity of population-based studies examining the IGF-liver cancer association, the pathophysiological mechanisms potentially involved will remain for subsequent investigation to elucidate. In conclusion, findings from this study suggest that IGF-I and IGFBP-3 may have independent roles in development of liver cancer. Confirmation of our results in other large, prospective population-based studies is needed, including examination of associations in women and nonsmokers. 


\section{REFERENCES}

Bosch FX, Ribes J, Diaz M, Cleries R (2004) Primary liver cancer: worldwide incidence and trends. Gastroenterology 127(5 Suppl 1): S5-S16

Buzzelli G, Dattolo P, Pinzani M, Brocchi A, Romano S, Gentilini P (1993) Circulating growth hormone and insulin-like growth factor-I in nonalcoholic liver cirrhosis with or without superimposed hepatocarcinoma: evidence of an altered circadian rhythm. Am J Gastroenterol 88(10): $1744-1748$

Chan JM, Stampfer MJ, Giovannucci E, Gann PH, Ma J, Wilkinson P, Hennekens CH, Pollak M (1998) Plasma insulin-like growth factor-I and prostate cancer risk: a prospective study. Science 279(5350): $563-566$

Chan JM, Stampfer MJ, Ma J, Gann P, Gaziano JM, Pollak M, Giovannucci E (2002) Insulin-like growth factor-I (IGF-I) and IGF binding protein-3 as predictors of advanced-stage prostate cancer. J Natl Cancer Inst 94(14): $1099-1106$

Dunn SE, Kari FW, French J, Leininger JR, Travlos G, Wilson R, Barrett JC (1997) Dietary restriction reduces insulin-like growth factor I levels, which modulates apoptosis, cell proliferation, and tumor progression in p53-deficient mice. Cancer Res 57(21): 4667-4672

Elsammak MY, Amin GM, Khalil GM, Ragab WS, Abaza MM (2006) Possible contribution of serum activin A and IGF-1 in the development of hepatocellular carcinoma in Egyptian patients suffering from combined hepatitis $\mathrm{C}$ virus infection and hepatic schistosomiasis. Clin Biochem 39(6): 623-629

Ferry Jr RJ, Katz LE, Grimberg A, Cohen P, Weinzimer SA (1999) Cellular actions of insulin-like growth factor binding proteins. Horm Metab Res 31(2-3): $192-202$

Hosmer DW, Lemeshow S (2000) Applied Logistic Regression, 2nd edn Wiley: New York

Iivonen J, Kela E, Kuusi M, Lyytikainen O, Ruutu P (2005) Infectious Diseases in Finland 1995-2004. National Public Health Institute: Helsinki

Jewell NP (2004) Statistics for Epidemiology. Chapman \& Hall/CRC: Boca Raton

Juul A (2003) Serum levels of insulin-like growth factor I and its binding proteins in health and disease. Growth Horm IGF Res 13(4): $113-170$

Korhonen P, Malila N, Pukkala E, Teppo L, Albanes D, Virtamo J (2002) The Finnish Cancer Registry as follow-up source of a large trial cohortaccuracy and delay. Acta Oncol 41(4): 381-388

London T, McGlynn K (2006) Liver Cancer, 3rd edn Oxford University Press: Oxford, New York

Lonn S, Inskip PD, Pollak MN, Weinstein SJ, Virtamo J, Albanes D (2007) Glioma risk in relation to serum levels of insulin-like growth factors. Cancer Epidemiol Biomarkers Prev 16(4): 844-846

Ma J, Pollak MN, Giovannucci E, Chan JM, Tao Y, Hennekens CH, Stampfer MJ (1999) Prospective study of colorectal cancer risk in men and plasma levels of insulin-like growth factor (IGF)-I and IGF-binding protein-3. J Natl Cancer Inst 91(7): 620-625

Major JM, Pollak MN, Snyder K, Virtamo J, Albanes D (2010) Insulin-like growth factors and risk of kidney cancer in men. $\mathrm{Br} J$ Cancer 103(1): $132-135$

Mattera D, Capuano G, Colao A, Pivonello R, Manguso F, Puzziello A, D'Agostino L (2003) Increased IGF-I: IGFBP-3 ratio in patients with hepatocellular carcinoma. Clin Endocrinol (Oxf) 59(6): 699-706
Mazziotti G, Sorvillo F, Morisco F, Carbone A, Rotondi M, Stornaiuolo G Precone DF, Cioffi M, Gaeta GB, Caporaso N, Carella C (2002) Serum insulin-like growth factor I evaluation as a useful tool for predicting the risk of developing hepatocellular carcinoma in patients with hepatitis $\mathrm{C}$ virus-related cirrhosis: a prospective study. Cancer 95(12): 2539-2545

McGlynn KA, Tsao L, Hsing AW, Devesa SS, Fraumeni Jr JF (2001) International trends and patterns of primary liver cancer. Int $J$ Cancer 94(2): $290-296$

Moschos SJ, Mantzoros CS (2002) The role of the IGF system in cancer: from basic to clinical studies and clinical applications. Oncology 63(4): $317-332$

Pavelic J, Matijevic T, Knezevic J (2007) Biological \& physiological aspects of action of insulin-like growth factor peptide family. Indian J Med Res 125(4): $511-522$

Peduzzi P, Concato J, Kemper E, Holford TR, Feinstein AR (1996) A simulation study of the number of events per variable in logistic regression analysis. J Clin Epidemiol 49(12): 1373-1379

Pollak M (2000) Insulin-like growth factor physiology and cancer risk. Eur J Cancer 36(10): 1224-1228

Renehan AG, Zwahlen M, Minder C, O’Dwyer ST, Shalet SM, Egger M (2004) Insulin-like growth factor (IGF)-I, IGF binding protein-3, and cancer risk: systematic review and meta-regression analysis. Lancet 363(9418): $1346-1353$

Rowlands MA, Gunnell D, Harris R, Vatten LJ, Holly JM, Martin RM (2009) Circulating insulin-like growth factor peptides and prostate cancer risk: a systematic review and meta-analysis. Int J Cancer 124(10): 2416-2429

Sachdev D, Yee D (2007) Disrupting insulin-like growth factor signaling as a potential cancer therapy. Mol Cancer Ther 6(1): 1-12

Scharf JG, Braulke T (2003) The role of the IGF axis in hepatocarcinogenesis. Horm Metab Res 35(11-12): 685-693

Shepard CW, Finelli L, Alter MJ (2005) Global epidemiology of hepatitis C virus infection. Lancet Infect Dis 5(9): 558-567

Shepard CW, Simard EP, Finelli L, Fiore AE, Bell BP (2006) Hepatitis B virus infection: epidemiology and vaccination. Epidemiol Rev 28: $112-125$

Stuver SO, Kuper H, Tzonou A, Lagiou P, Spanos E, Hsieh CC, Mantzoros C, Trichopoulos D (2000) Insulin-like growth factor 1 in hepatocellular carcinoma and metastatic liver cancer in men. Int J Cancer 87(1): $118-121$

The ATBC Cancer Prevention Study Group (1994) The alpha-tocopherol, beta-carotene lung cancer prevention study: design, methods, participant characteristics, and compliance. The ATBC Cancer Prevention Study Group. Ann Epidemiol 4(1): $1-10$

Woodward M (2005) Epidemiology: Study Design and Data Analysis, 2nd edn Chapman \& Hall/CRC: Boca Raton

Wu JC, Daughaday WH, Lee SD, Hsiao TS, Chou CK, Lin HD, Tsai YT, Chiang BN (1988) Radioimmunoassay of serum IGF-I and IGF-II in patients with chronic liver diseases and hepatocellular carcinoma with or without hypoglycemia. J Lab Clin Med 112(5): 589-594

Yu H, Jin F, Shu XO, Li BD, Dai Q, Cheng JR, Berkel HJ, Zheng W (2002) Insulin-like growth factors and breast cancer risk in Chinese women. Cancer Epidemiol Biomarkers Prev 11(8): 705-712 